\title{
Cogeneration in a Hospital: a case Study
}

\author{
C. J. Renedo, A. Ortiz, D. Silió, M. Mañana, S. Pérez and J. Carcedo \\ Department of Electric and Energy Engineering \\ ESTI Industriales y Telecomunicación, University of Cantabria \\ Av Los Castros s/n, 39005 Santander (Spain) \\ Phone: +34 942 201382, fax: +34 942 201385, e-mail: renedoc@unican.es
}

\begin{abstract}
In this paper the authors analyze different alternatives to provide energy utilities to a hospital center with cogeneration systems with diesel engines and gas turbines. The study considers several power sizes and control strategies, so it shows the influence of these parameters, showing that in this case the options with diesel engines are more efficient than the equivalent ones with gas turbines.
\end{abstract}

\section{Key words:}

Cogeneration, Diesel Engine, Gas Turbine, Thermal Energy, Electricity

\section{Introduction}

Usually, hospitals are great consumers of energy, as much electrical as thermal. The last one can take different forms: hot water, space heating, or cool water for the air conditioning. The reduction of these consumption contributes not only to an economic improvement in the operation of the hospital, but also the reduction of polluting emissions that cause the greenhouse effect, as well as the reduction of the hospital dependency of the external power supply.

In order to get that the facilities work efficiently, it is necessary to make a study of the different alternatives, before the design is undertaken.

In this paper, two different cogeneration types for a hospital center are analyzed, one with diesel engines and another one with gas turbines. For each facility, two different control strategies are studied. The analysis of the results allows to find one solution that optimizes values as the energy consumption, the yield or the emission reduction of $\mathrm{CO}_{2}$.

\section{The Hospital}

The Hospital consist of 25 buildings with about 80,000 $\mathrm{m}^{2}$, and more than 1,000 beds. It is located in the city of Santander and is one of the reference Hospital center in the Spanish North Coast. A summary of the climatology data in that area [1] is included in Table I.

\section{Power demand in the Hospital}

The power demand of the Hospital can be divided in thermal demand, that consists of space heating, hot tap water and air conditioning systems; and electrical demand. It is necessary to notice that initially, the cold demand for air conditioning it is also an electrical demand, since the method to produce cool water is supported with chillers driven by electrical compressors.

The annual thermal demand of the Hospital has been divided in three periods based on the heating necessities:

1) Winter: high space heating and hot tap water demand, very slight need of air conditioning (operating rooms).

2) Spring-autumn: demand of hot tap water, and very slight of air conditioning

3) Summer: demand of hot tap water and high demand of air conditioning

In each one of the three periods four intervals have been considered, these are necessary for the different demand of hot tap water during the day. Anyway the other thermal demands are also variable, since the occupation of the buildings depends fundamentally on the schedule of the doctors. So, the following periods of time were:

TABLE I.- Santander Climatology Data.

\begin{tabular}{|c|c|c|c|c|c|c|c|c|c|c|}
\hline \multirow[b]{2}{*}{ atitude $^{o}$} & \multirow[b]{2}{*}{ ongitud $^{o}$} & \multirow[b]{2}{*}{ Elevation } & $\mathrm{He}$ & & \multicolumn{6}{|c|}{ Cooling } \\
\hline & & & \multicolumn{2}{|c|}{ Dry Bulb } & $\begin{array}{c}\text { Dry } \\
\text { Bulb }\end{array}$ & $\begin{array}{l}\text { Wet } \\
\text { Bulb }\end{array}$ & $\begin{array}{l}\text { Dry } \\
\text { Bulb }\end{array}$ & $\begin{array}{l}\text { Wet } \\
\text { Bulb }\end{array}$ & $\begin{array}{c}\text { Dry } \\
\text { Bulb }\end{array}$ & $\begin{array}{l}\text { Wet } \\
\text { Bulb }\end{array}$ \\
\hline \multirow{2}{*}{$43,47 \mathrm{~N}$} & \multirow{2}{*}{$3,82 \mathrm{~W}$} & \multirow{2}{*}{$64 \mathrm{~m}$} & $99,6 \%$ & $99 \%$ & \multicolumn{2}{|c|}{$0,4 \%$} & \multicolumn{2}{|c|}{$1 \%$} & \multicolumn{2}{|c|}{$2 \%$} \\
\hline & & & 2,3 & 4 & 26,5 & 19,5 & 24,7 & 19,4 & 23,7 & 19 \\
\hline
\end{tabular}


1) $8 \mathrm{~h}$ to $15 \mathrm{~h}$ : high hot tap water demand

2) $15 \mathrm{~h}$ to $20 \mathrm{~h}$ : moderate hot tap water demand

3) $20 \mathrm{~h}$ to $24 \mathrm{~h}$ : slight hot tap water demand

4) $24 \mathrm{~h}$ to $8 \mathrm{~h}$ : almost null hot tap water demand, only the losses caused by the water circulation in the pipe network.

The demand of hot tap water of the Hospital does not depend on the period of the year, but on the moment of the day. The non exact coincidence of the daily time intervals in the three periods of the year is a consequence of the annual variation of the income water temperature in the Hospital network [2].

The thermal demand data of the Hospital can be observed in the Table II. There, the thermal necessities based on the different annual periods and daily intervals are presented. In figure 1 the data are expressed monthly.

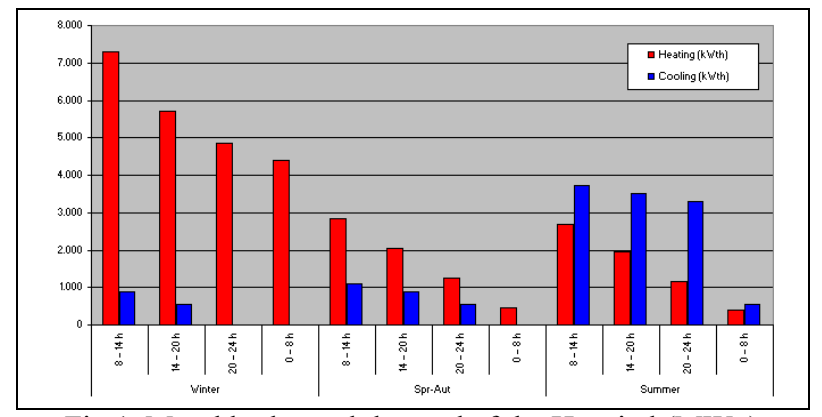

Fig 1. Monthly thermal demand of the Hospital $\left(\mathrm{MW}_{\mathrm{th}}\right)$

The cold necessities cause a yearly electrical demand of approximately 3,035 $\mathrm{MWh}_{\mathrm{e}}$; two third parts of this demand takes place in peak hours, being the remaining third in valley hours.

The annual electrical demand of the Hospital, including the necessary one for the cold production is more than $13,535 \mathrm{MWh}_{\mathrm{e}} /$ year, of which approximately $75 \%$ are made in peak hours. The whole energy is provided by the local electrical company. In figure 2 the monthly electrical demand is shown.

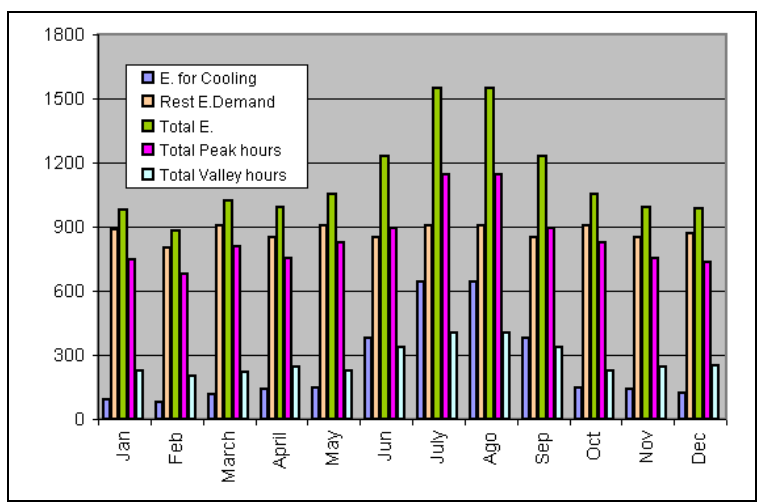

Fig 2. Monthly electrical demand of Hospital $\left(\mathrm{MWh}_{\mathrm{e}}\right)$

\section{Reference case}

The reference case studied, figure 3 , is the initial (current) facilities in the Hospital, that had to supply the heat demand with conventional boilers, whereas the refrigeration system is based in water chillers driven by electrical compressors. The electrical energy for chillers and the rest of consumptions is taken from the urban network

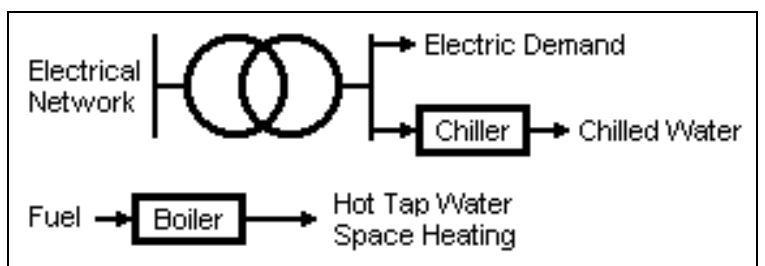

Fig 3. Reference case

Taking into account the annual heating demand, 22,200 $\mathrm{MWh}_{\mathrm{th}}$, and considering that the seasonal boilers performance is $85 \%$, the production must be of 26,000 $\mathrm{MWh}_{\text {th. }}$. The fuel used was natural gas, whose cost by $\mathrm{kWh}_{\text {th }}$ is $0.022458 €$, so, the annual cost in heating energy is $586,000 €$.

On the other hand, the annual cold demand reaches 8,950 $\mathrm{MWh}_{\mathrm{th}}$. The chillers coefficient of performance is 2.95,

TABLE II.- Thermal necessities of the Hospital $\left(\mathrm{kW}_{\mathrm{th}}\right)$

\begin{tabular}{|c|c|c|c|c|c|}
\hline \multicolumn{2}{|c|}{ Thermal Demand } & \multicolumn{3}{c|}{ Heating } & Cooling \\
\hline \multirow{4}{*}{ Period } & Interval & $\begin{array}{c}\text { Hot Tap Water } \\
\left(\mathrm{kW}_{\text {th }}\right)\end{array}$ & $\begin{array}{c}\text { Space Heating } \\
\left(\mathrm{kW}_{\mathrm{th}}\right)\end{array}$ & $\begin{array}{c}\text { Total } \\
\left(\mathrm{kW}_{\text {th }}\right)\end{array}$ & $\begin{array}{c}\text { Total } \\
\left(\mathrm{kW}_{\text {th }}\right)\end{array}$ \\
\hline \multirow{5}{*}{ Winter } & $8-14 \mathrm{~h}$ & 3,093 & 4,200 & 7,293 & 878 \\
\cline { 2 - 6 } & $14-20 \mathrm{~h}$ & 2,209 & 3,800 & 5,679 & 548 \\
\cline { 2 - 6 } & $20-24 \mathrm{~h}$ & 1,326 & 3,800 & 4,844 & \\
\cline { 2 - 6 } & $0-8 \mathrm{~h}$ & 442 & 4,200 & 4,387 & \\
\hline \multirow{5}{*}{ Spring-Autumn } & $8-14 \mathrm{~h}$ & 3,012 & & 2,846 & 1,097 \\
\cline { 2 - 6 } & $14-20 \mathrm{~h}$ & 2,151 & & 2,033 & 878 \\
\cline { 2 - 6 } & $20-24 \mathrm{~h}$ & 1,291 & & 1,220 & 548 \\
\cline { 2 - 6 } & $0-8 \mathrm{~h}$ & 430 & & 2,692 & 3,731 \\
\hline \multirow{5}{*}{ Summer } & $8-14 \mathrm{~h}$ & 2,849 & & 1,923 & 3,511 \\
\cline { 2 - 6 } & $14-20 \mathrm{~h}$ & 2,035 & & 1,154 & 3,292 \\
\cline { 2 - 6 } & $20-24 \mathrm{~h}$ & 1,221 & & 385 & 548 \\
\hline
\end{tabular}


TABLE III.- Summary of the annual power consumptions and its respective costs

\begin{tabular}{|c|c|c|c|c|c|c|c|c|c|}
\hline \multicolumn{2}{|c|}{ Heating } & \multicolumn{4}{c|}{ Cooling } & \multicolumn{4}{c|}{ Rest of electricity } \\
\hline $\mathrm{MWh}_{\text {th }}$ & $€ /$ year & $\mathrm{MWh}_{\mathrm{e}}$ & $€ /$ year & $\mathrm{MWh}_{\mathrm{e}}$ & $€ /$ year & $\mathrm{MWh}_{\mathrm{e}}$ & $€ /$ year & $\mathrm{MWh}_{\mathrm{e}}$ & $€ /$ year \\
\hline 22,200 & 586,000 & 2,000 & 165,000 & 1,034 & 39,000 & 8,200 & 677,000 & 2,300 & 86,500 \\
\hline
\end{tabular}

and approximately two thirds of the electrical consumption is made in peak hours, whereas in the valley hours the remaining third is demanded. Moreover, the electrical tariff is $0.0375 € / \mathrm{kWh}_{\mathrm{e}}$ in peak hours, and $0.00826 € / \mathrm{kWh}_{\mathrm{e}}$ in valley hours, resulting approximately a total cost of $204,000 € /$ year for the cool production.

The rest of the hospital facilities need 10,500 $\mathrm{MWh}_{\mathrm{e}}$ altogether; the electrical power demand is approximately $2,050 \mathrm{~kW}_{\mathrm{e}}$ in the peak hours of the working days, 300 $\mathrm{kW}_{\mathrm{e}}$ in the nocturnal hours, and $775 \mathrm{~kW}_{\mathrm{e}}$ in the diurnal hours during holidays. So, the total cost of the rest of the electricity consumed reaches 763,600 €/year.

In Table III, the different annual power consumptions for the reference case and its associated costs are shown. The total costs are approximately $1,553,500 € /$ year.

\section{Cogeneration alternatives}

In this section, different cogeneration alternatives with diesel engines and gas turbines are analyzed. The possible solutions in which the steam took part were discarded beforehand, due to the complexity and the difficulties of its handling for the Hospital maintenance personal.

Cogeneration systems do not represent a problem in the case of producing more electric energy than the necessary for the own consume, since the Spanish Law establish that this extra energy must be absorbed by the Electrical Company. Moreover, these systems not only can represent a power and economic saving for the Hospital, but is also a security against possible failures of the electrical supply, decreasing the Hospital external dependency.

In order to optimize cogeneration facilities, the ideal situation would be that the thermal demand of the Hospital was uniform during the day and the year. Nevertheless, this does not happen and the demand suffers important variations. So, if the alternatives are calculate to cover the maximum thermal demands, then during many hours per year the facilities are going to work at low load, or even they are going to be shutdowns. For this reason it is necessary to have special care of at the time of selecting the cogeneration power, since an excessive size leads to solutions that are not economically attractive.

To decide on the power of the cogeneration facilities the thermal demand have to be studied, otherwise a heat excess is produced and must be dissipated outside. If the amount of heat is great, it implies that the installation does not fulfil the equivalent electrical yield required by the law to be declared as cogenerator. Therefore, the electrical company is not forced to buy the excess of electrical production. On the other hand, the adopted solutions not only must watch economic aspects, but also energy and environmental aspects, that tend to increase the facilities efficiency, avoiding unnecessary fuel consumptions.

For each one of the cogeneration studied solutions two different alternatives were considered:

1) maximize the electrical production

2) maximize the time of use at full load

The first of the alternatives means greater cogeneration size, since to maximize the electrical production, the installation must be designed based on the maximum thermal demand, situation that takes place in winter. It should take into account that the cogeneration should work properly at partial load in periods where the thermal demand is lower, as autumn and spring, and the cogeneration must work at partial load, since the operation have to follow the thermal demand.

In the second option, the installation is designed based on the minimum thermal demand, that happens in summer, since this way the facilities can work all the year at full load, taking permanently advantage of the high efficiency of the cogeneration system. During the periods of great thermal demand, this must be satisfied by auxiliary boilers.

Another important aspect are the electrical tariffs, since the existence of tariffs that charge depending on the hour of the day, determines the operation program of the facilities. Considering the price difference in the $\mathrm{kWh}_{\mathrm{e}}$ between the valley hours tariff and the peak one, one reaches the conclusion that the cogeneration power station must remain shutdown during the valley hours (nocturnal schedule and non working days). The reason is that the $\mathrm{kWh}_{\mathrm{e}}$ bought in nocturnal tariff is cheaper than the produced by the cogeneration. This makes that the cogeneration use is 16 hours per day (8-24h), 250 days per year $(4,000$ hours per year).

\subsection{Cogeneration with diesel engines}

The alternative consists of the installation of one or several diesel engines whose axis drives an electrical generator. As electrical and thermal yields of this installation the values of $36 \%$ and $48 \%$ have been considered, respectively [5].

This way, part of the electrical energy that requires the Hospital is produced there and at the same time residual 
heat is obtained from the refrigeration water of the engines and also from the exhaust gases. The resulting hot water is used to satisfy the space heating and hot tap water demands. In case that the thermal demand is more than what the cogeneration supplies, conventional boilers will be necessary to provide the total thermal demand.

On the other hand, the cool water needs for the air conditioning are covered with chillers driven by an electrical compressor. The general operation scheme of this option is shown in figure 4.

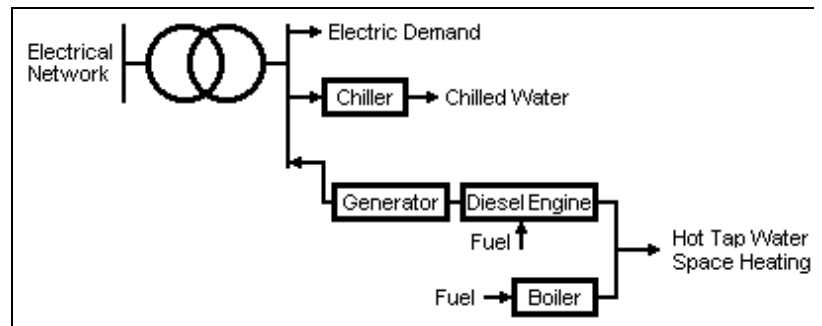

Fig 4. Operation scheme of cogeneration with diesel engines

\subsubsection{Cogeneration with diesel engines and maximum electrical production}

In this option a cogeneration facility of $4,000 \mathrm{~kW}_{\mathrm{e}}$ has been considered. In order to avoid reducing the installation performance, the engines should work near its rated load. This is the reason why was decided to divide the total power between two engines of 2,500 and 1,500 $\mathrm{kW}_{\mathrm{e}}$, what allows the engines to work no far from the rated load during all the periods they have to.

For this option the thermal balance demand-production during the working days and the monthly electrical balance are shown in figures 5 and 6 .

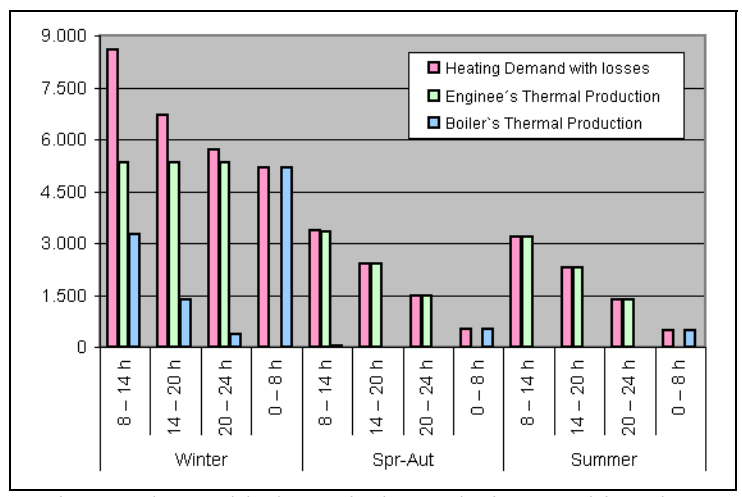

Fig 5.- Thermal balance in $\mathrm{kW}_{\mathrm{th}}$ during working days with two engines of 2,500 and $1,500 \mathrm{~kW}_{\mathrm{e}}$

The cogeneration is able to provide almost all the heat required by the Hospital in the working days of summer, spring and autumn, covering a very significant part of the winter thermal demand, figure 5.

The helping boilers have to provide the thermal energy that the cogeneration is not able to supply, but in addition they have to have sufficient power to cover the Hospital thermal demand when the cogeneration is stopped, by a failure or during holidays or weekends. Therefore, the total power has to be at least equal to the maximum thermal demand, $7,300 \mathrm{~kW}_{\text {th }}$. This total power of boilers is independent of the alternative considered.

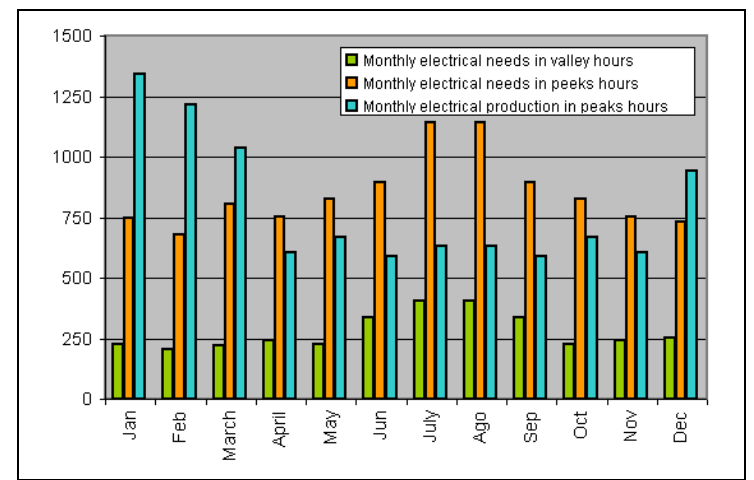

Fig 6.- Monthly electrical balance in $\mathrm{MWh}_{\mathrm{e}}$ with two diesel engines of 2,500 and $1,500 \mathrm{~kW}_{\mathrm{e}}$

Figure 6 shows how in the winter months, and due to the strong demand of heating, the electrical production in peak hours would be greater than the demand, whereas the rest of the year would be lower than the demand. In the non winter periods the thermal demand is quite low, and therefore the cogeneration would work under its rated power. Globally, the system generates $70 \%$ of the Hospital total electrical consumption.

In figure 7 the annual distributions of production, demand, buy and sell of electrical energy in the Hospital in the peak hours of the working days are observed.

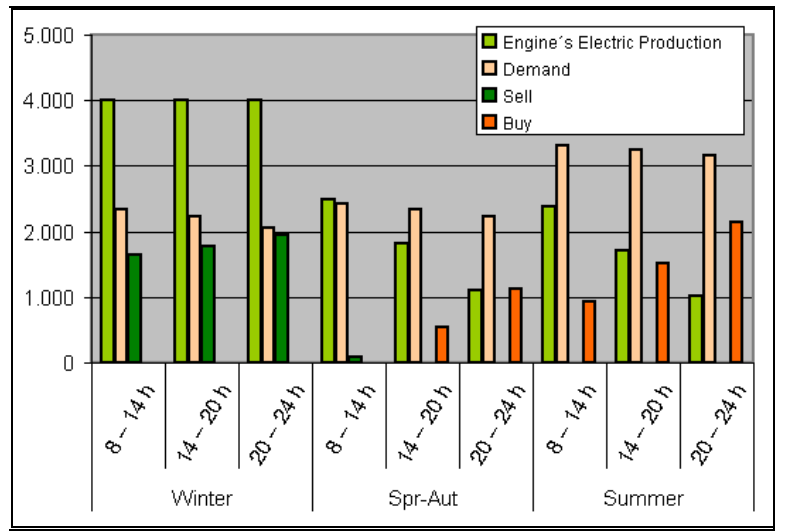

Fig 7.- Production, demand, buy and sell of electrical energy in the peak hours of the working days in $\mathrm{kW}_{\mathrm{e}}$ with two diesel engines of 2,500 and $1,500 \mathrm{~kW}_{\mathrm{e}}$

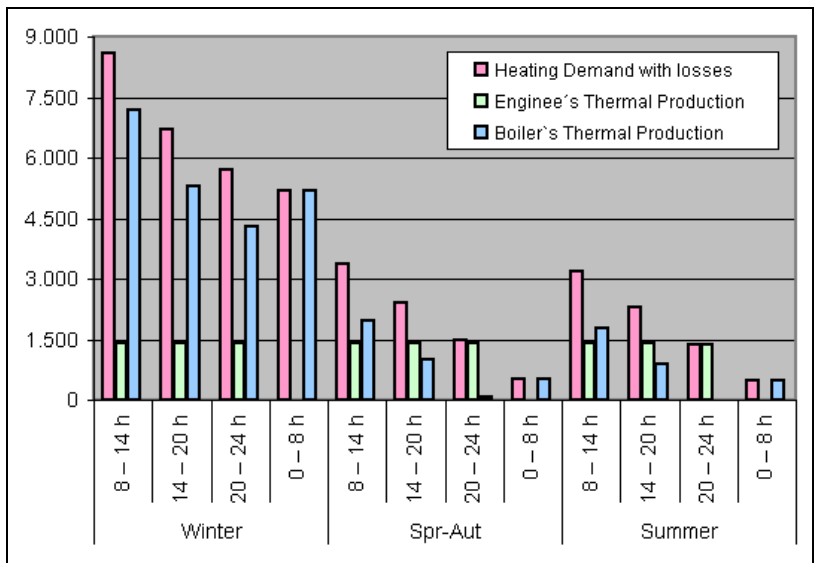

Fig 8.- Daily thermal balance in $\mathrm{kW}_{\text {th }}$ during the working days with one diesel engine of $1,050 \mathrm{~kW}_{\text {th }}$ 


\subsubsection{Cogeneration with diesel engines and maximizing the use at full load}

In this second option, the cogeneration with diesel engine considers continuous operation of a $1,050 \mathrm{~kW}_{\mathrm{e}}$ engine at full load. The engine power is chosen based on the engine thermal production, since is the one that satisfy the minimum demand of the Hospital during the operation schedule of the cogeneration. The daily thermal demand and production in the working days and the monthly electrical demand and production are shown in Figs 8 and 9.

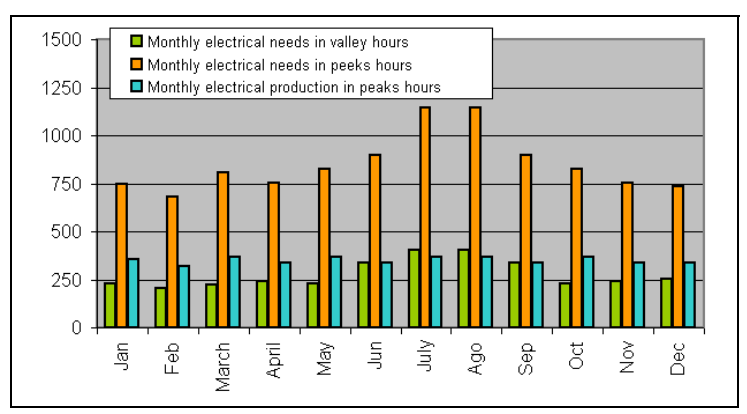

Fig 9.- Monthly electrical balance in $\mathrm{MWh}_{\mathrm{e}}$ with one diesel engine of $1,050 \mathrm{~kW}_{\mathrm{e}}$

The cogeneration works at full load during all the year, except in the nocturnal schedule and holidays, in which remains shutdown, figure 8 . The electrical production is quite constant all the year, around the $31 \%$ of the Hospital needs, which is inferior to the one of the previous case, figure 9.

In figure 10 the production, demand, buy and sell of electrical energy in the peak hours of the working days is shown. The Hospital does not export at any moment electrical energy to the network.

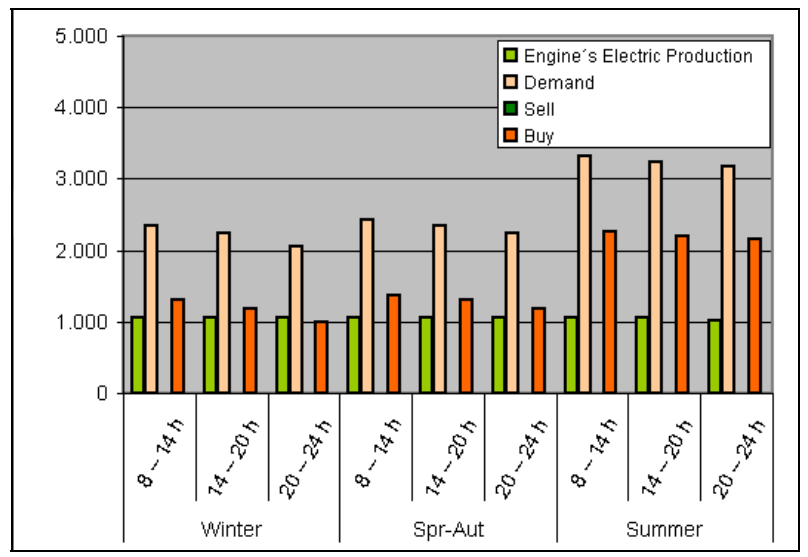

Fig 10. - Production, demand, buy and sell of electrical energy in peak hours of the working days in $\mathrm{kW}_{\mathrm{e}}$ with one $1,050 \mathrm{~kW}_{\mathrm{e}}$ diesel engine

\subsection{Cogeneration with gas turbines}

The second of the proposed solutions is based on gas turbines. The operation principle is similar to the one of the diesel engines, nevertheless it presents at least the following differences:
- Although the global yield of the gas turbines is slight superior to the one of the diesel engines, 86 to $84 \%$, the distribution between the thermal and electrical yields it is very different, for a gas turbines 55.5\% and $30.5 \%$ has been considered, respectively [5].

- Another aspect is that in the gas turbines the heat can only be recovered from the exhaust gases and does not exist refrigeration water of the turbine.

- The gas turbine have a low yield at partial load. For diesel engine the yield is much better in that situation.

- In the case of the gas turbines, for small powers, the price per installed $\mathrm{kW}$ of the cogeneration becomes excessive, decreasing at the same time the electrical yield.

\subsubsection{Cogeneration with gas turbines and maximum electrical production.}

For this alternative a power generation of $4,000 \mathrm{~kW}_{\mathrm{e}}$ has been considered. In order to avoid that the cogeneration have to work at partial load, which would reduce the performance seriously, the power production has been divided between two gas turbines of 2,650 and 1,350 $\mathrm{kW}_{\mathrm{e}}$.

The daily thermal balance in the working days, and the monthly electrical balance are presented in figures 11 and 12.

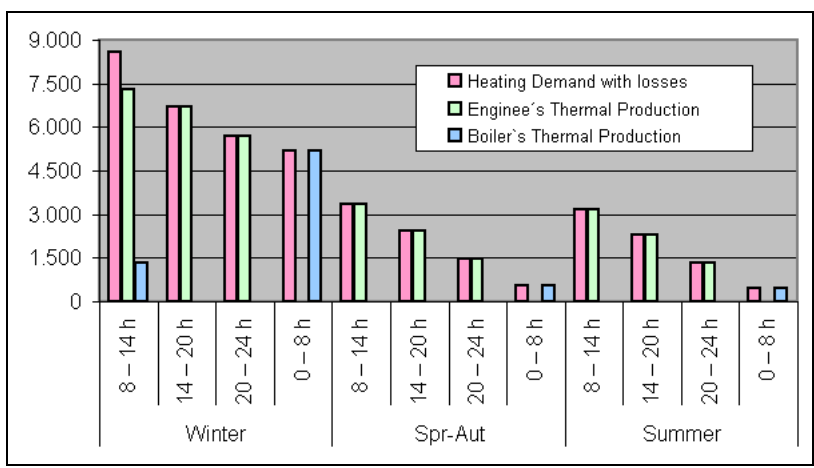

Fig 11. - Daily thermal balance in $\mathrm{kW}_{\text {th }}$ with two gas turbines of 2,650 and $1,350 \mathrm{~kW}_{\mathrm{e}}$

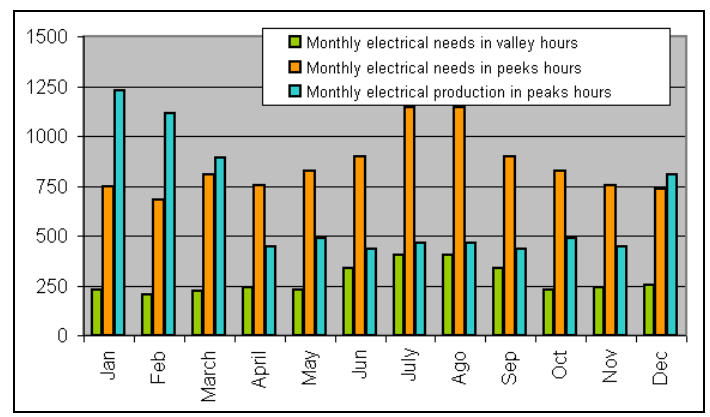

Fig 12. - Monthly electrical balance in $\mathrm{MWh}_{\mathrm{e}}$ with two gas turbines of 2,650 and $1,350 \mathrm{~kW}_{\mathrm{e}}$

Figure 11 shows how the cogeneration is able to cover great part of the annual thermal demand. This cogeneration type improves the behavior of the one with diesel engines what is due to the greater thermal 
production of the gas turbines in comparison to the one of the diesel engines.

As it is observed in figure 12, the months of winter, and due to the strong demand of heating, the electrical production would be higher than what is necessary, whereas the rest of the year would be lower. Therefore the cogeneration would have to work with one turbine stopped, and the other at partial load. Globally is generated $57 \%$ of total electrical consumption, quite inferior to $70 \%$ obtained with the same facility power but with diesel engines.

In figure 13 the annual distribution of the production, demand, buy and sell of electrical energy on the Hospital in peak hours of the working days are observed.

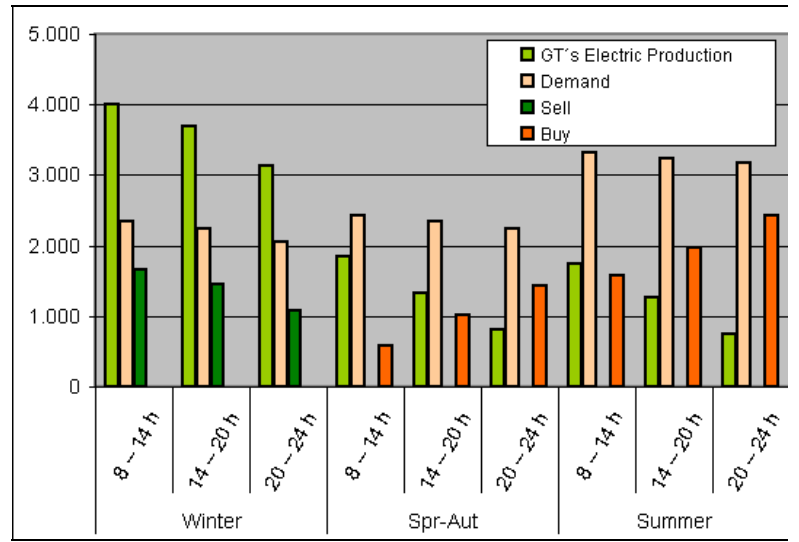

Fig 13.- Production, demand, buy and sell of electrical energy in peak hours of the working days in $\mathrm{kW}_{\mathrm{e}}$ with two gas turbines of 2,650 and $1,350 \mathrm{~kW}_{\mathrm{e}}$

\subsubsection{Cogeneration with gas turbines and full load use}

In this case, the cogeneration with gas turbines will work at full load most of the time, avoiding to work at partial load. So an only $1,000 \mathrm{~kW}_{\mathrm{e}}$ gas turbine has been considered. The heat balance in the working days, and the monthly electrical balance are shown in figures 14 and 15 .

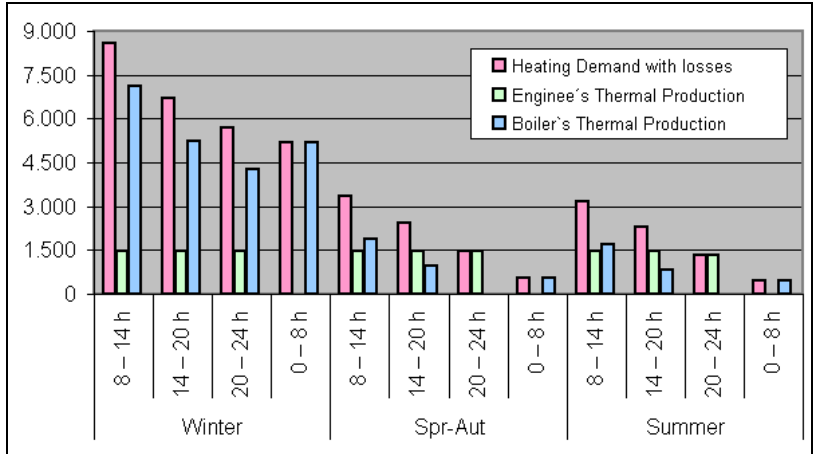

Fig 14. - Thermal balance in $\mathrm{kW}_{\text {th }}$ during the working days with one gas turbine of $1,000 \mathrm{~kW}_{\mathrm{e}}$

This cogeneration system is only able to cover a small part of the thermal demand, figure 14, nevertheless is working at full load all the year. The electrical production, figure 15, is far lower than the previous case, so the electrical production is the $23.5 \%$ of the Hospital needs.

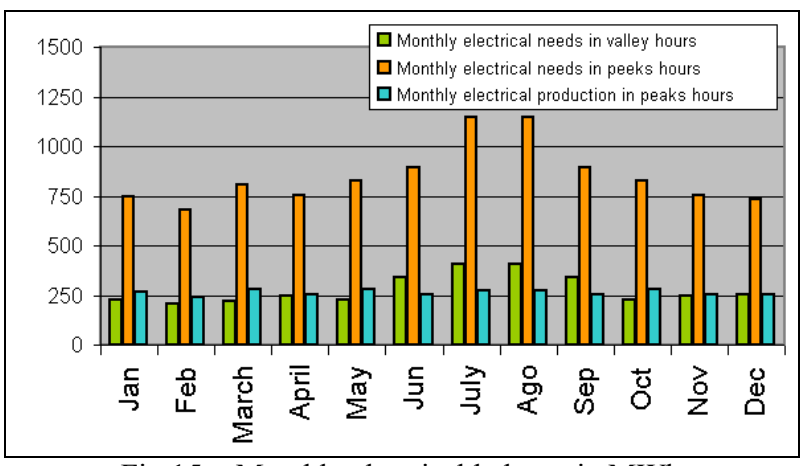

Fig 15. - Monthly electrical balance in $\mathrm{MWh}_{\mathrm{e}}$ with one gas turbine of $1,000 \mathrm{~kW}_{\mathrm{e}}$

In figure 16 is showed the buy and sell of electrical energy in the working days, being also observed that the Hospital does not export at any moment electrical energy to the network.

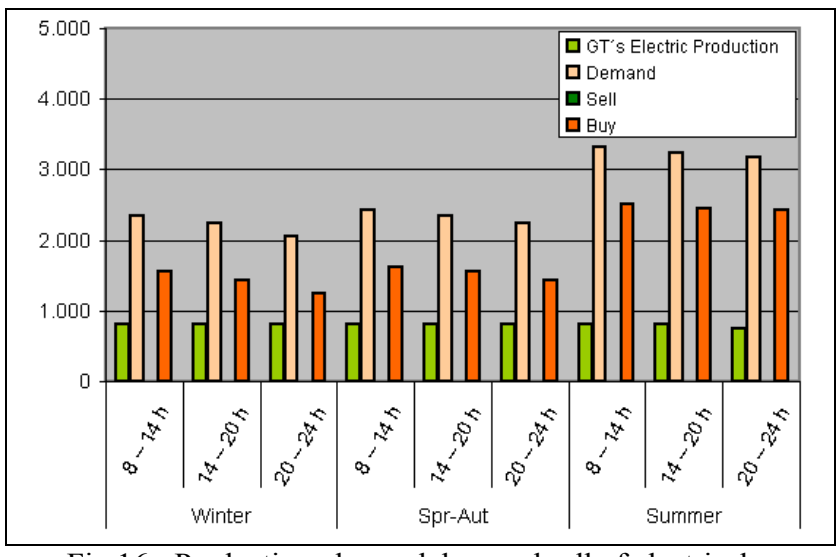

Fig 16.- Production, demand, buy and sell of electrical energy in the peak hours of the working days in $\mathrm{kW}_{\mathrm{e}}$ with one gas turbine of $1,000 \mathrm{~kW}_{\mathrm{e}}$

\section{Cost analysis}

With respect to the installation and operation costs, and due to the number of different alternatives, has not been made a detailed economic study, but it can be given some general rules on the yield of the investments.

Regarding to the installation costs of the different alternatives, it has been decided not to consider the one of the auxiliary boilers. The reason is that in each one of the four considered options, the sum of the boilers power is the same, and equal to the reference installation. So, it has been considered that this value does not establish significant differences, since the only difference is how the total power is distributed between the different boilers to cover the lack of heat that the cogeneration does not provide in the different periods at full load.

As operation costs, the totals per year have been considered, that is to say, the total of electricity, and those of fuels of boilers and cogeneration.

\subsection{Installation Costs}

The installation cost has been determined considering diverse cogeneration projects made in Spain, in which 
has collaborated the government, IDAE [3]. From the analysis of these projects the results summarize in figure 17 has been obtained.

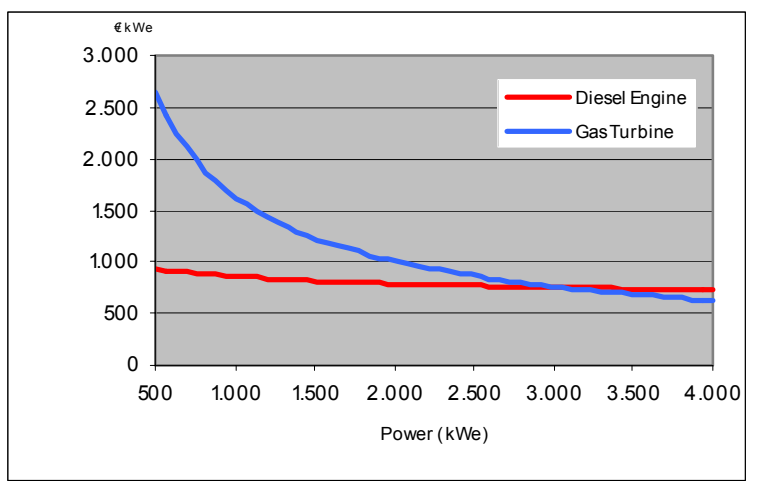

Fig 17. - Cogenerations investment costs with diesel engines and gas turbines

The total installation costs of the different alternatives considered are presented in Table IV.

TABLE IV.- Cogenerations estimated costs $(€)$

\begin{tabular}{|c|c|c|c|}
\hline $\begin{array}{c}\text { Cog. Diesel } \\
\text { Engine (1) }\end{array}$ & $\begin{array}{c}\text { Cog. Diesel } \\
\text { Engine (2) }\end{array}$ & $\begin{array}{c}\text { Cog. Gas } \\
\text { Turbine (1) }\end{array}$ & $\begin{array}{c}\text { Cog. Gas } \\
\text { Turbine (2) }\end{array}$ \\
\hline $3,161,600$ & $1,004,400$ & $4,046,250$ & $1,620,000$ \\
\hline
\end{tabular}

\subsection{Operation Costs}

The annual operation costs, classified in boilers, cogeneration and electricity; in the base situation and in the different alternatives considered, as well as the annual not being observed great differences between the equivalent options of diesel engine or gas turbine.

The annual analysis of costs of all the studied alternatives is shown in figure 18. So, the cogeneration options with maximum electricity production present higher savings, not being observed great differences between the equivalent options of diesel engine or gas turbine.

The economic study has taken an interest rate of $5 \%$, and an installation working life of 10 years. In figure 19, the yield, the cash flow, and the necessary investment in each one of the four studied alternatives, are shown saving with respect to the base situation, are shown in Table $\mathrm{V}$.

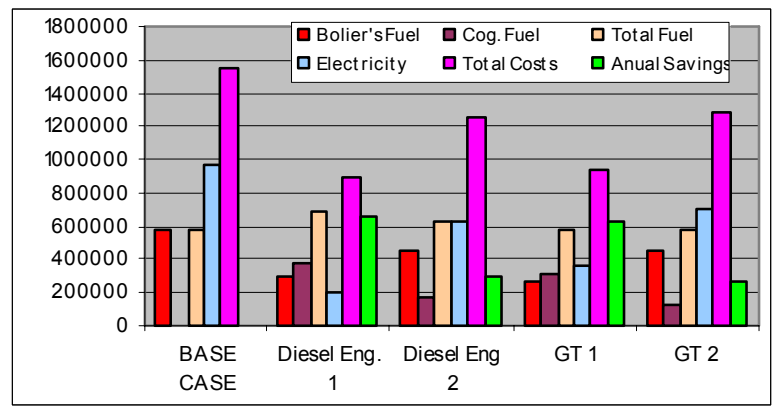

Fig 18. - Costs in $€$ of all the considered alternatives

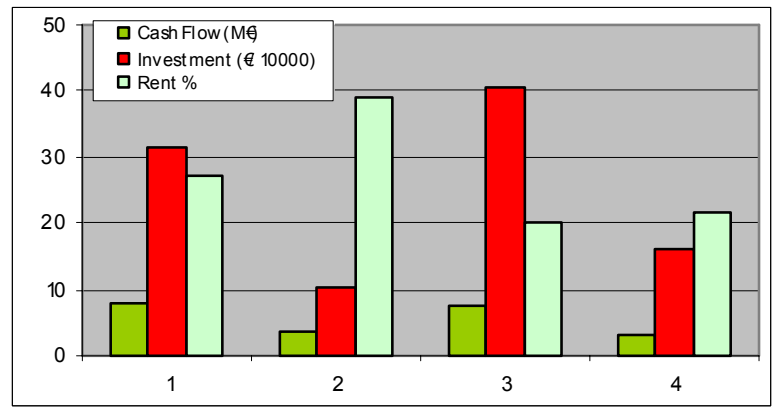

Fig 19.- Yield, cash flow and investment of the four studied alternatives

From the analysis in figure 19 it is deduced that the options with diesel engines are better than the equivalent one with gas turbines, although, the global yield of the gas turbines is greater than the one of the engines. This is based mainly on two aspects:

- for small powers, as it is the case of this study, the investment cost of the turbines is considerably greater than the one of the engines.

- the facilities performance is strongly bound to the electrical production, and the production ratio of the engines is considerably greater to the one of the turbines.

The investment that presents the greatest profitability is to use a diesel engines at the maximum electrical production, this is because the operation at full load is the most frequent situation.

Nevertheless the option that produces the greatest total economic saving is the cogeneration with diesel engines

TABLE V.- Operation Costs $(€ / 1000)$

\begin{tabular}{|c|c|c|c|c|c|c|}
\hline \multicolumn{2}{|c|}{ Costes (€/año) } & Base Case & Diesel Eng.(1) & Diesel Eng. (2) & G.T. (1) & G.T. (2) \\
\hline \multicolumn{2}{|c|}{ Boilers fuel } & 586 & 300 & 460 & 271 & 456 \\
\hline \multicolumn{2}{|c|}{ Cogeneration fuel } & - & 381 & 168 & 308 & 127 \\
\hline \multirow{2}{*}{$\begin{array}{c}\text { Buy } \\
\text { Elect. }\end{array}$} & Peak & 842 & 203 & 496 & 322 & 580 \\
\hline & Valley & 125 & 125 & 125 & 125 & 125 \\
\hline \multicolumn{2}{|c|}{ Sell Elect. } & - & 118 & - & 93 & - \\
\hline \multicolumn{2}{|c|}{ Annual Cost } & 1,553 & 892 & 1,249 & 933 & 1,288 \\
\hline \multicolumn{2}{|c|}{ Annual savings } & - & 661. & 304 & 620 & 266 \\
\hline
\end{tabular}


and maximum electrical production, this is because it is in this situation in which the greatest amount of electricity in peak hours is produced, being this the most expensive energy.

\section{Conclusions}

During the development of this work it has been shown that any of the four proposed alternatives improves the current operation results. This conclusion should make great energy consuming centers, as Hospitals are, to consider seriously the possibility of implanting a cogeneration system. So, in these centers the economic resources can be dedicated to sanitary services, and not to pay power extra-costs for the energy.

Moreover the cogeneration presents other additional advantages, apart of the merely economic ones, since it reduces electrical disturbances in the power system, providing a more stable and safe operation to the set of electrical equipment of the Hospital. In case of a severe failure in the network, the power station could provide, with support of extra generation groups if it were necessary, electrical energy to the whole Hospital, which is a guarantee given the special characteristics of the "client".

In the future, not only this type of power systems have to be considered, but also trigeneration with cool production machines by absorption, especially in the countries of the South of Europe, where the necessities of refrigeration in summer are important. These facilities would allow that the cogeneration work at full load during longer periods of the year, and therefore can contribute to an important improvement of the yield, since more electricity is produced.

In Spain, due to the generalized use of domestic air conditioning equipments, the maximum electrical demand has been transferred to the months of winter to summer, reason why the trigeneration will contribute, not only to a greater economic yield of the facilities, but also will unload the national infrastructure of generation, distribution and supply of electrical energy.

\section{Acknowledgement}

The authors wish to thank the support given by all the members of the hospital "Marqués de Valdecilla" of Santander.

\section{References}

[1] ASHRAE, Fundamentals Handbook 2001

[2] Energías Renovables 4, Ed El Instalador, 2003 (in spanish)

[3] IDAE, El IDAE y la cogeneración, 1999 (in spanish)

[4] PROTERMO, Guidelines for Calculating Energy Generation in Combined Heat and Power Plants

[5] PROTERMO, Manual for calculating CHP electricity and heat 